\section{BASF Acquires Parts of Ciech's TDI Business}

B ASF has announced the acquisition of parts of Ciech's global TDI (toluene diisocyanate) business - subject to approval by the appropriate antitrust authorities. Closing of the transaction is expected in the first quarter of 2013.

The production facility of Ciech's subsidiary Zachem, Poland, is not part of the transaction. Ciech and BASF will cooperate closely to facilitate an effective transition of supply agreements and support services for Ciech's TDI customers

"This acquisition underlines our strong commitment to the TDI markets in Europe, the Middle East, Africa and worldwide”, said Raimar Jahn, President of BASF's Polyurethanes division. "We are looking forward to establishing a successful partnership with Ciech's customers." BASF's strong commitment to the TDI business is also illustrated by the construction of the world's largest single-train TDI plant in Ludwigshafen.

Dariusz Krawczyk, President of the Management Board of Ciech, added: "We are confident that with BASF we have found the ideal purchaser for our TDI business. Our customers will benefit from BASF's broad knowledge and experience in the polyurethanes market and its strong global set-up."

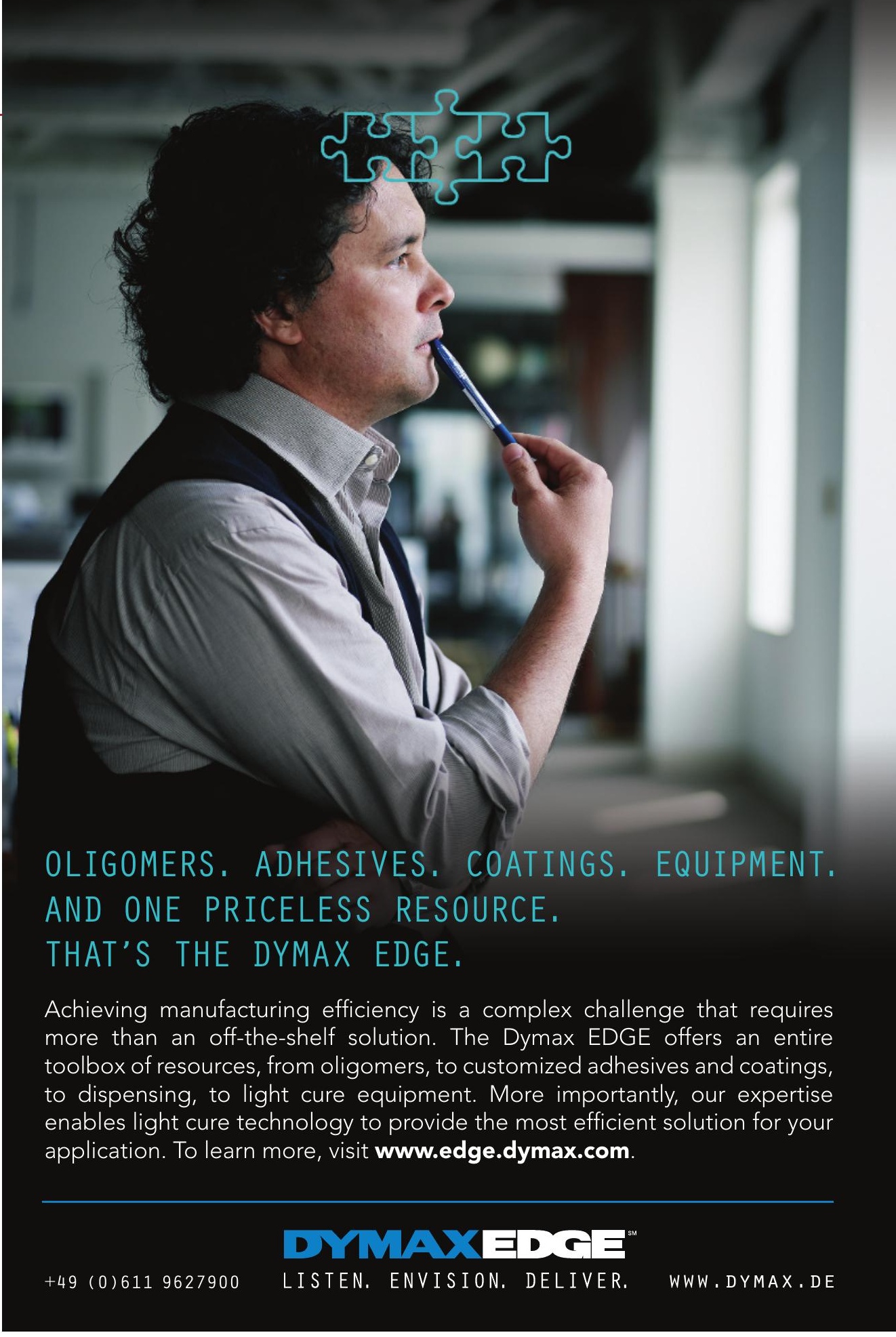

\title{
Innomatec Founds Production Company in China
}

$T$ he company Innomatec, a special of leak testing and functional testing, has now opened a new production plant in Taicang (Suzhou Province) to the west of Shanghai. Although it has more than one million inhabitants, Taicang is still regarded as a small town by Chinese standards. The newly formed company, called Innomatec China Test and Special Equipment, is one of 150 German companies supply- ing Asian markets or exporting to Germany from their base in Taicang.

In addition, a Sales and Service Office was opened in Shanghai City in March this year with the aim of serving customers in the Shanghai area even more quickly and efficiently.

The management team is also expecting Innomatec China to become established as a leak testing expert in China, as automation starts to increase in the east of China and qua- lity improvement measures are being introduced. According to the company management, the foundation activities have created the basis for achieving a major part of the growth planned for Innomatec $\mathrm{GmbH}$ in China.

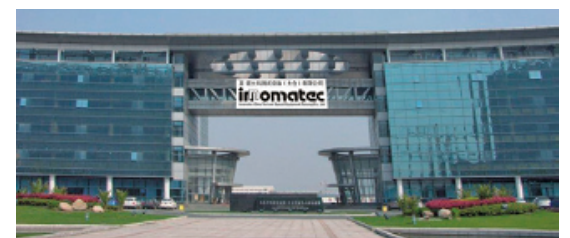

